\title{
Lexis
}

Journal in English Lexicology

12 | 2018

Lexical and Semantic Neology in English

\section{Gender-biased neologisms: the case of man-X}

Océane Foubert and Maarten Lemmens

\section{(2) OpenEdition}

\section{Journals}

Electronic version

URL: http://journals.openedition.org/lexis/2453

DOI: $10.4000 /$ lexis. 2453

ISSN: 1951-6215

\section{Publisher}

Université Jean Moulin - Lyon 3

\section{Electronic reference}

Océane Foubert and Maarten Lemmens, "Gender-biased neologisms: the case of man-X », Lexis

[Online], 12 | 2018, Online since 14 December 2018, connection on 19 April 2019. URL : http:// journals.openedition.org/lexis/2453; DOI : 10.4000/lexis.2453

This text was automatically generated on 19 April 2019

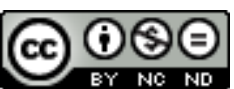

Lexis is licensed under a Creative Commons Attribution-NonCommercial-NoDerivatives 4.0 International License. 


\title{
Gender-biased neologisms: the case of man-X
}

\author{
Océane Foubert and Maarten Lemmens
}

\section{Introduction}

Gender is repeatedly discussed in various areas these days, and in particular in the (social) media, and new trends need to be addressed and named. ${ }^{1}$ In fact, the current increased (and still increasing) gender-awareness is accompanied by the appearance of gendered coinages, such as bromance (bro + romance), girlboss, manbun or ShEO (she + CEO). ${ }^{2}$ This article presents a semantic analysis of one specific type of such gendered coinages that we will refer to as "man-neologisms" since they all follow the formal template man-X, combining the lexeme man with another lexical item (or part of a lexical item, in the case of blends), such as man bun, mancation or manspread. The term "neologism" will be used in this paper regardless of the degree of diffusion of the lexemes. Analysing the meaning of man-neologisms presents the perfect opportunity to capture the current gender discussion, at least for English.

More specifically, for this study (based on Foubert [2018]), we have analysed the semantic structure of 1,403 such man-neologisms. As detailed below, our study reveals that man in these coinages only rarely carries a generic meaning (referring to human beings in general, as in man is mortal) but mostly has a gender-specific meaning ("of, or related to, men"). Our analysis of the meanings of these man-specific neologisms shows that they are gender specific as they mainly designate domains which are typically associated with women. Moreover, our analysis reveals four underlying motivations for coining manneologisms: (i) the (re)appropriation of domains which are typically associated with women, as in man purse (a purse for men), (ii) the reinforcement of differences, such as man cave (a room for men only), (iii) the confirmation of stereotypes, as in man science (a branch of knowledge available to men only), (iv) and naming undesirable male behaviours, mainly in an attempt to change them, such as mansplain (men explaining things to women in a condescending way). Furthermore, our frequency-based diffusion analysis (based on 
the iWeb corpus) reveals that man-neologisms aiming at the reappropriation of domains, and more particularly, those naming undesirable male behaviours are less likely to be coined but more inclined to be diffused, as opposed to neologisms reinforcing differences and confirming stereotypes.

Concerning the formal side of these neologisms, as the examples above show, two main types were found, blends and compounds. While there is a clear difference between the two processes in terms of productivity, we will not make this distinction in our analysis, since the current study does not aspire to determine the productivity of the word formation process itself, but to uncover the (semantic-pragmatic) motivations that underlie these coinages.

The article is structured as follows. Section 1 below briefly presents the linguistic literature on gender focusing on the representation of gender in language (male generics) as well as the literature on neologisms. In Section 2, we will present the methodology and data underlying the current study. Section 3 gives the main results of our two qualitative investigations on the meanings of man-neologisms. Finally, Section 4 gives the main results of our quantitative study on the diffusion of these neologisms. In the conclusion, we present a short summary of our findings and sketch avenues of further research.

\section{Gender and language}

\subsection{Gender and language studies}

Linguistic research on gender can be divided into two main categories: (i) studies on the representation of gender in language and (ii) studies of differences in language use and conversational behaviour as depending on the sex of the speaker. While the latter has been repeatedly discussed in the past century, taking the form of discourse analysis (Haas [1944]; Lakoff [1975]; Tannen [1990]), only recently has the former been the object of more systematic corpus-based studies (see, e.g., Schmid [2003]).

Research focusing on the representation of gender in language has also been addressed in a contrastive linguistic perspective (e.g., Hellinger \& Bußmann [2001], [2002], [2003], [2015]). A widely spread practice found across languages is the use of male generics, which is the subject of numerous discussions. Male generics, also referred to as generic masculines for languages with grammatical gender, correspond to the use of male forms to describe both men and women. For example, in English, it is possible to use the pronoun he (and its variants) to refer to both women and men or when the sex of the person referred to is unknown, as in an American drinks his coffee black (Hellinger \& Bußmann [2003]). This practice is not constrained to pronouns. For instance, in French, masculine forms of nouns are used to refer to both men and women or when the sex of the referent is unknown, as in habitants (m.pl) 'inhabitants' or enseignants (m.pl) 'teachers'. In the feminist literature, this practice is interpreted as men's construal of gender-biased language to reinforce their superiority and women's invisibility, as the male form is used as the norm (see Spender [1980]). The feminist movement in the 1960s and 1970s did not react so much to the use of male generics, but rather encouraged women to become active in the language process by coining woman-centred words to name their experiences, such as sexism, sexual harassment and patriarchal.

More recently, the use of male generics has been addressed in the movement for genderfair language (a.k.a. gender-neutral or inclusive language), which promotes the use of 
alternative forms to male generics, but also gender-marked words in general. For example, singular they is used more and more as the generic pronoun and so are genderneutral words such as police officer or cabin crew instead of policeman or steward(ess). In addition, there are recent initiatives discouraging language that might cause offence to the LGBTQI community; for this reason, the use of gender-neutral terms, such as parent, is encouraged over exclusionary expressions such as mum and dad. In the case of languages with grammatical genders, such as French, when the referent's sex is unknown or includes both men and women, one can use so called inclusive forms, where both genders are simultaneously marked. For instance, if one wants to refer to both male and female students, the inclusive form étudiant.e.s (m.f.pl) 'students' is often used instead of the generic masculine form étudiants (m.pl). Often, this only works in orthography. The use of gender-fair language is encouraged by prestigious institutions, such as UNESCO, but the degree of institutionalisation of these forms can greatly vary across countries and languages (Sczesny et al. [2016]). Nevertheless, this approach reveals the awareness of gender representation in language.

Moreover, various studies addressing male generics have questioned this generic aspect. Recently, the idea of language as male-biased has received empirical support, as studies show that male generics are not understood as generics but as man-specific, subsequently influencing mental representations (see Stahlberg et al. [2007] or Sczesny et al. [2016] for a comprehensive overview). For example, studies have investigated words designating professions - an oft-cited characteristic of male and female differences - and have found that children and adults associate professions with a specific gender, depending on the grammatical form of job titles, which suggests that linguistic forms do influence mental representations (Chatard et al. [2005]; Gaucher et al. [2011]; Vervecken et al. [2013]. For example, Chatard et al. [2005] show that the use of the masculine generic in French instead of a more neutral form to name occupations affects girls' perceptions of these occupations. Despite the growing literature on gender and language, which focuses on male generics and advocates language change, few studies have investigated more recent gender-driven usage of language. One of these is the recent tendency to coin gendered words and the current article reports on one kind of such coinages, "man-neologisms", a study which provides valuable insights to the representation of gender in English.

\subsection{On the significance of analysing neologisms to study gender and language}

The tendency to coin gendered words in the current context of gender-awareness provides valuable insights into the representation of gender in English. As Schmid [2016: 69] - our emphasis - states:

[N]ew words are continually being added to the lexicon, generally because new objects are being invented and new ideas are arising, all requiring a designation. In addition, words which are not strictly speaking 'required' for naming purposes are created to encapsulate new trends and social practices.

In other words, the need for new words highlights the social dimension of language. With respect to newly created gendered words, they not only aim at describing a new 'reality' to be shared with others, but they also address the social issue of gender and its current depiction in language. More remarkably, gendered coinages reveal a gap between institutions and usage. While the growing linguistic literature on gender shows how problematic gendered language is - hence encouraging language change through the use 
of neutral forms - the new coinages may appear in contradiction with this call for neutralisation, as they build on lexemes such as man, mum, she, he, guy, bro, or girl to build new words. This article aims at providing a more detailed semantic analysis of one of these, viz. coinages using man as their first element, such as man bun, manspread or man cave; as indicated, these will be referred to as "man-neologisms".

The term neologism is commonly used to designate new words which are relatively well diffused, in opposition to ad-hoc formations (Fischer [1998: 3]; Schmid [2016: 75]). We will, however, use the term neologism regardless of their diffusion, i.e. regardless of whether they are ad-hoc formations or conventionalised words, as this aspect is beyond the scope of the current study. Schmid [2016] proposes three perspectives to be considered in the analysis of neologisms: (i) the structural perspective, (ii) the sociopragmatic perspective, and (iii) the cognitive perspective. The structural perspective studies the internal structure of words, such as their form, meaning, and context dependency (Bauer [1983]). The sociopragmatic perspective considers neologisms in the speech community, studying their uses and familiarities in context (Wurschinger et al. [2016]). The cognitive perspective studies neologisms in the minds of speakers focusing on their entries in the mental lexicon and conceptual status (Kemmer [2003]; Lehrer [1996]). In these three perspectives, various stages of the development of new words can be studied, from their origin to their establishment. The current study adopts a structural perspective, considering the meaning of neologisms. Moreover, we consider the degree of diffusion of these neologisms via a frequency analysis based on Internet data (the iWeb corpus, see below). For reasons of feasibility, our corpus study is quantitative, looking at the frequency of the neologisms; it does not present a qualitative analysis of the context of use of these neologisms. While an analysis of such contextual information on the use of these neologisms (e.g., who uses them, gender and age of the speakers, social influence, etc.) would be relevant, the data collected via the Internet as we use here rarely provide such information on users.

\section{Data and method}

\subsection{Collecting man-neologisms}

The neologisms analysed in this study have been drawn from two crowd-sourced usercontent based websites: The Open Dictionary (Merriam-Webster) and Urban Dictionary ${ }^{3}$. The words had to be collected manually for two reasons: first of all, these websites do not enable an automatic extraction of their words and meanings and secondly, each of these words had to be considered individually to make sure that, in addition to starting with the lexeme man, they referred to either a generic or man-specific meaning. For example, manicism has not been selected, since it comes from manic which has no link with the lexeme man. Given that the number of man-neologisms in The Open Dictionary was not exceedingly high, all 90 of them have been selected for further analysis. However, the sheer quantity of man-neologisms in the Urban Dictionary (estimated to be around 5,700) does not allow such an exhaustive manual extraction. As a result, we have extracted the data from this dictionary in a random fashion by selecting words that start with man followed by the letters $a, b, c$ (3 subsequent letters at the onset of the alphabet) and $r, s$, and $t$ ( 3 subsequent letters in the middle of the alphabet). For example, we have selected man adventure, man breakfast, manchild (first random set), man right, manscort (man + escort), 
and manterrupt (man + interrupt) (second random set), but not mandaddy or man unicorn (the second element starting with $d$ and $u$ respectively). This has yielded a sample of 1,313 formations, which brings the total of man-neologisms to 1,403. While not exhaustive, this sample is judged to be sufficiently large and reliable to reveal pertinent tendencies and their motivations. It should be pointed out that when it comes to neologisms, any selection is bound to be non-exhaustive, since new words are coined on a daily basis.

While the meaning of man-neologisms remains the main concern of this study, their form has been observed too. On the whole, man-neologisms follow the predominant coinage patterns. The great majority of neologisms are compounds (794) composed of two constituents, such as man brain, man cave or man-flu, but blends are also quite common (561), e.g., manologue (man + monologue), manstache (man + moustache) or manteraction (man + interaction). In simple terms, blends can briefly be defined as the combination of two source words where one of the source words is usually shortened, as in manstache, or where the two source words overlap, as in manalyze (man + analyze) (Gries [2004], [2012]). The form of some man-neologisms remains unknown (or uncertain) as the second source word could not be identified, hence the impossibility to determine their types, as in mansher (designating a man hopelessly chasing a woman he likes, possibly man + chase + her).

\subsection{Coding}

The sample of 1,403 man-neologisms was subsequently analysed for a number of semantic features. Firstly, we coded whether the neologisms were generic or gender-specific. When the gender-specific meaning was not made explicit in the definitions or in the examples, it was considered as having a generic meaning.

Secondly, a more detailed analysis was carried out on the man-specific neologisms which are the main focus of the current investigation; in total, there are 1,374 man-specific neologisms. These have been analysed for various semantic features which aim at uncovering the motivations underlying these formations. Our starting hypothesis is that man-neologisms are man-specific because they denote entities which are typically associated with women. In order to determine whether a neologism denotes a domain which is typically associated with men or women, it was necessary to identify these typically male or female domains, relying on empirically sound evidence. Schmid's [2003] article analysing male and female discourse in the BNC provided a good starting point for doing so. His corpus-based analysis identified certain discourse topics (referred to as domains) as predominantly male or female. Such preponderances in discourse reflect the main fields of interest of men and women. While this does not mean that these domains themselves (i.e. in the 'world out there') can be regarded as male or female, one can assume that domains that are predominant in women's discourse are regarded as stereotypically associated with women and their preoccupations, domains predominant in men's discourse, with men, and other domains (not in Schmid's article) are regarded as neutral. In this article, we will use the term domain as a handy shortcut to refer to "domains that are stereotypically conceptualised as, or associated with, either male or female". Importantly, these stereotypical associations may not always hold; for example, FOOD \& DRINK are preponderant in female discourse, but beer is most likely stereotyped as belonging to the male domain. This is a point we will come back to below (when 
discussing words such as manbeer). ${ }^{4}$ The distribution of each domain that we have distinguished is presented in Table 1.

Table 1: Distribution of domains

\begin{tabular}{|c|c|c|}
\hline & DOMAINS & EXAMPLES FROM OUR SAMPLE \\
\hline \multirow{6}{*}{ FEMALE } & BODY AND HEALTH & manatomy (man + anatomy), man beard, manorexia (man + anorexia) \\
\hline & CLOTHING & mancessory (man + accessory), manpurse, mansuit \\
\hline & FEELING & man blush, mantastic (man + fantastic), mantears \\
\hline & FOOD AND DRINK & manbeer, man breakfast, manshot, \\
\hline & HOME & man cave, manchore, manthroom (man + bathroom) \\
\hline & RELATIONSHIP & man crush, man date, mantrimony (man + matrimony) \\
\hline \multirow{3}{*}{ MALE } & ABSTRACT NOTIONS & man brain, manconomics (man + economics), man science \\
\hline & ENTERTAINMENT & mancanoe, man club, man surfing \\
\hline & WORK & man boss, manny (man + nanny), mansseuse (man + masseuse $)$ \\
\hline \multirow{3}{*}{ NEUTRAL } & BEHAVIOUR & manbition (man + ambition), man code, manstupid \\
\hline & INVENTION & manchine (man + machine), manserpent, mansheep \\
\hline & SEX & mancest (man + incest), mansex, mantercourse (man + intercourse) \\
\hline
\end{tabular}

The domain FEeLING does not figure in the list of domains in Schmid's article, but is regarded as related to RELATIONSHIP (as it mainly involves another person in the definitions). ENTERTAINMENT is not in Schmid's paper either, but mainly involves SPORTS, a domain that is present in his paper. It is also possible that words refer to several domains, as in manriod (man + period) where the dictionary definition contains references to both the domains BODY AND HEALTH and BEHAVIOUR.

Our analysis of the motivations underlying coinages of man-neologisms and their representations of gender focuses on the man-specific aspect, i.e. how these words are made to refer to 'maleness'. Not only do man-neologisms specify this male aspect, they also designate how they do so. For example, man-flu designates a flu that is male because it is only contracted by men; thus, in this case, the male aspect corresponds to the exclusion of women. In general, man specifies the male aspect by establishing a particular relation between genders (the relation being the exclusion of women in the case of manflu). In total, nine such relations have been identified and categorised as male-oriented, female-oriented or neutral relations. Six of these are male-oriented relations:

- "male equivalence": refers to neologisms denoting the male version of an entity in a relatively direct way, as in manorexia defined as "the male version of anorexia nervosa." (UD 2018-05-18) ${ }^{5}$ 
- "exclusion of women": refers to neologisms which explicitly exclude women, as in man-flu in which the definition clarifies "women do not contract man-flu." (UD 2018-05-18)

- "reinforcement of the male aspect": refers to neologisms which highlight the male aspect, as in man beard defined as "an exemplary display of manliness." (UD 2018-05-18)

- "majority of men": refers to neologisms designating things that apply to men more than women, as in manconomics defined as "an economics classroom [...] that is mostly dominated by men." (UD 2018-05-18)

- "male explanation": refers to neologisms designating a (mainly undesirable) behaviour explained by the fact that it is male (because they are men, they act in a specific way) as in " manterrupt: a type of gendered bullying, akin to mansplaining, in which a man continuously interrupts a woman or women in order to dominate a conversation." (UD 2018-05-18)

When none of the characteristics are specified, man is used as a neutral reference to men ( of a man), as in manscarf designating men's hairiness. (UD 2018-05-18)

Man-neologisms can also denote entities with women as the main referent, in that case relations are regarded as female-oriented relations. Here are the two relations identified in the data sample:

- "female equivalence": refers to neologisms denoting the typical male aspect of a female entity, as in manceps (man + biceps) defined as "an unfeminine condition [...] which leaves arms looking overtly masculine." (UD 2018-05-18)

- When neologisms do not refer to the typical male aspect, neutral references to women are made, as in "man book: a woman's romantic novel." (UD 2018-05-18)

The remaining type, the neutral relation, concerns man-neologisms covering to both men and women while still being man-specific, as in man stoopid (sic) designating an act of stupidity that typically only men do, but which can be performed by both men and women.

\section{Semantic analysis of man-neologisms}

\subsection{Man-neologisms and genericity}

The gender-fair language approach advocates the neutralisation of language through the use of alternative forms for male generic terms, such as chairperson instead of chairman. Man-neologisms, such as man code or manterrupt, may seem in contradiction with the idea of a more neutral language. ${ }^{6}$ One could argue that this need not be so, for two reasons.

First, man-neologisms need not be in conflict with gender-fair language, since it is the generic use of man (referring to both men and women) which is considered problematic, not its gender-specific use (referring to men). In other words, the conflict with genderfair language only arises in generic uses of man- $X$ coinages (which given its entrenchment for the X-man pattern remains a possibility), not with exclusive references to men (or to women, for woman-based neologisms).

We thus need to determine whether the meaning of man in these neologisms is generic or specific. Of the 1,403 neologisms in our sample, only 29 are used with the generic meaning of man as opposed to 1,374 that are man-specific $\left(X^{2}=1289.4, \mathrm{df}=1, \mathrm{p}<2.2 \mathrm{e}-16\right) .{ }^{7}$ Overall, the generic meaning was used to refer to invented entities like chimeras, such as mantar (man + guitar; half human, half guitar), mansheep (half human, half sheep), and manster (man + 
monster; half human, half monster), or from a human origin such as manstone (a manmade stone) and man scoup (sic) (using one's hand as a spoon).

Given that our data reveal that the generic use of man is in fact not the predominant one in these man-neologisms, one could conclude that they are not in opposition with genderfair language. However, male generics are not the only forms criticised in the gender-fair language approach. Promoting neutral forms such as flight attendant rather than the gendered forms steward/stewardess creates the (strong) suggestion that any type of gender-marker is to be avoided. In this view, the gender-specific man-neologisms (the vast majority of forms attested in the two dictionaries) may still be problematic for the gender-fair language, precisely because they are gender marked.

A second argument that could be levelled against the idea that the gender-specific manneologisms are in conflict with gender-fair language is that most of the man-neologisms discussed here are not the 'gendered words' usually targeted by feminists, since they do not designate people but entities (e.g., manbun, mankini, etc.). ${ }^{8}$ However, this argument does not really hold. When speakers encounter a novel word such as these manneologisms, the meanings of the parts are retrieved in an attempt to understand the meaning of the whole (Schmid [2016: 74]). For example, to understand or compute the meaning of manccessories or man purse, speakers need to retrieve (i.e. cognitively activate) the meaning of man and accessories / purse. In other words, as our study shows, even manneologisms referring exclusively to men or things associated with men activate (stereotypical) associations that are usually built in reference to female domains.

In sum, strictly speaking gender-specific man-neologisms are not at odds with genderneutral language which invariably concerns references to people. At the same time, it cannot be denied that the strong tendency to coin such neologisms (as attested by their sheer quantity in the dictionaries) represents a move towards increased gender-specific language and suggests a need for speakers to specify that something is (stereotypically) 'male' (one way or another). The motivations for this need do strike at the heart of the gendered representations (stereotypes) as reflected in language, as will be detailed in the following part.

\subsection{The motivation of gender-specific man-neologisms}

The vast majority of man-neologisms in our sample build on a gender-specific reading of the lexeme man. Behind this prolific construction lies a need to specify what is male, but what are the underlying motivations for this need? We hypothesize that man-neologisms are man-specific because they denote entities that are predominantly associated with women. To test the hypothesis, the concepts expressed were first classified in two categories: those pertaining to female domains (6 domains) versus those pertaining to non-female domains (6 domains). Neologisms designating women as the main referent ( female-oriented relations), such as man book (a woman's romantic novel), have been deliberately excluded, to reduce potential bias toward female domains. In other words, we only retained neologisms where female domains were mobilised 'in reference to men'.

Table 2: Distribution of domains (with male-oriented and neutral relations)

\begin{tabular}{|l|l|l|}
\hline DOMAINS & N & $\%$ \\
\hline
\end{tabular}




\begin{tabular}{|c|c|c|c|}
\hline FEMALE & BODY AND HEALTH & 434 & $34.1 \%$ \\
\hline & CLOTHING & 51 & $4.0 \%$ \\
\hline & FEELING & 23 & $1.8 \%$ \\
\hline & FOOD AND DRINK & 32 & $2.5 \%$ \\
\hline & HOME & 17 & $1.3 \%$ \\
\hline & RELATIONSHIP & 145 & $11.4 \%$ \\
\hline & SUBTOTAL FEMALE domains & 702 & $55.2 \%$ \\
\hline MALE & ABSTRACT NOTIONS & 6 & $0.5 \%$ \\
\hline & ENTERTAINMENT & 64 & $5.0 \%$ \\
\hline & WORK & 14 & $1.1 \%$ \\
\hline & SUBTOTAL MALE domains & 84 & $6.6 \%$ \\
\hline NEUTRAL & BEHAVIOUR & 375 & $29.5 \%$ \\
\hline & INVENTION & 15 & $1.2 \%$ \\
\hline & SEX & 95 & $7.5 \%$ \\
\hline & SUBTOTAL NEUTRAL domains & 485 & $38.2 \%$ \\
\hline TOTAL & & 1,271 & $100 \%$ \\
\hline
\end{tabular}

Female domains are referred to 702 times (55.2\%), non-female domains, 569 times (44.8\%). This difference is statistically significant $\left(X^{2}=13.917, d f=1, p=0.000191\right)$. The hypothesis predicting that man-neologisms designate concepts which are typically associated with women is thus confirmed.

While a quantitative analysis confirms the general hypothesis, it remains difficult to interpret the results, as man-neologisms raise numerous questions. Even though the words significantly designate female domains, the motivations for why this should be so remain unclear. One motivation could be the reappropriation of a domain to establish equality and to erase differences at the semantic level, as in mankini (man + bikini), the male version of bikini. Conversely, marking the gender could reinforce differences, by providing a way for men to differentiate themselves from women and thus also possibly reinforce stereotypes, as could be argued to be the case for manfingers designating strong and reassuring fingers of 'real' men (as opposed to, for example, manicured and wellgroomed fingers of the metrosexual man). In order to answer these questions, both the domains and the meanings of man need to be examined. Crossing the domains and the relations enabled us to identify four main motivations underlying the coinages: (i) the reappropriation of domains, (ii) the reinforcement of differences, (iii) the confirmation of 
stereotypes, and (iv) the undesirability of male behaviours. These are taken up in turn in the next section. Overall, the analysis shows that despite sharing a common structure, man-neologisms subsume various meanings and motivations. For example, while most man-neologisms designate entities which are indeed typically associated with women, as in mankini, they can also refer to entities that generally have been defined as part of a female domain, but which are in fact typically associated with men, as in man beer (within the overall female domain FOOD AND DRINK).

\subsubsection{The reappropriation of domains}

The first motivation we suggest for coining man-neologisms is the reappropriation of female domains into the male domain. Some of these man-neologisms project an exact correspondence between what is usually associated with women and which now is to be associated with men. In other words, these neologisms simply designate the male version of an entity which belongs to a typically female domain, without adding any features to make the entity (stereotypically) male. This is particularly true for neologisms referring to CLOTHING, such as mankini (a bikini for men) or manpurse (a purse for men). It is also the case of neologisms referring to RELATIONSHIPS and HOME, such as mandle (man + candle; a candle for men), manden name (man + maiden name) or manstress (man + mistress). In short, the reappropriation could be seen as an attempt to erase gender differences; however, this interpretation does not hold.

First of all, some man-neologisms refer to the female domains with no intention to erase differences, as clearly shown by example (1) depicting a partial equivalence between men and women.

(1) manorexia: The male version of anorexia nervosa [...]. This eating disorder is commonly seen in starlets but is now affecting men, where they take on the wasted appearance of starving children in third world countries. This is more often a drug-related issue in men than the self-esteem issue it manifests in women. (UD 2018-05-18)

Furthermore, the interpretation that reappropriation of domains serves to erase differences becomes problematic when the neologisms designate and/or focus on distinguishing physical features, such as breasts, as in man bops or manboob, but also menstruation with a relatively neutral description of a specific behaviour, as shown by example (2).

(2) manrof: stands for "man rage of fury" and represents the seasons of which men show the symptoms of pms, including bitchiness, crabbiness, crankiness, a need for chocolate, and being an overall douche for no reason. Coined by Amy Gallegos from CFHS. (UD 2018-05-18)

While the interpretation that the coinage of man-neologisms is triggered by the achievement of equality of domains remains a possibility for some neologisms, the depiction of partial equivalences and distinguishing features shows that it cannot be the only one. Further analysis of the data lends support to another interpretation of domain reappropriation, viz. the (simultaneous) reinforcement of differences. On top of depicting partial correspondence between men and women, the male aspect of such words can also be highlighted, which is the case of neologisms referring to FOOD AND DRINK, and BODY AND HEALTH, as in the following examples. 
(3) man slushie: A margarita for a man. Preferably without any umbrellas or fancy shit like salt. (UD 2018-05-18)

(4) man-sturizer (man + moisturizer): A face product marketed to manly men and metrosexuals who want to moisturize their face while still maintaining a modicum of their masculinity. (UD 2018-05-18)

As opposed to the previous examples depicting neutral references to men and/or women, such as man purse (the male version of a purse), neologisms such as man slushie or mansturizer add another meaning to the male version of an entity: it is male and, more specifically, manly.

In sum, man-neologisms can be coined for the reappropriation of female domains to erase gender differences, as some neologisms denote full correspondences between what is typically associated with women and is now to be associated with men. However, the interpretation of the elimination of differences is problematic with those neologisms which denote a partial correspondence (as in manorexia), those which highlight the male aspect (as in man-sturizer), or those which focus on distinguishing characteristics (as in manboob). Despite a possible intention of erasing differences and achieving equality of domains, a competing and more plausible interpretation is the reinforcement of differences, discussed next.

\subsubsection{The reinforcement of differences}

The second motivation underlying man-neologisms is the reinforcement of inter-gender differences (between men and women) as well as intra-gender differences (among men). Various strategies are used to achieve such reinforcement.

The most straightforward way in which man-neologisms reinforce the differences between men and women is to shift the focus on what distinguishes them. As mentioned above, neologisms referring to BODY AND HEALTH - supposedly a component of the WOMAN frame - highlight what typically characterises and distinguishes men from women. Out of 366 references to this domain, 203 involve male sexual organs such as man butter, man region, and man stick. Another frequently mentioned characteristic is hairiness, as in mansweater, man snuggy, manscarf or man beard.

Distinctions between men and women are also at issue in neologisms concerning hierarchy or superiority (with men depicted as superior or as inferior to women), but also the exclusion of women, as in the following examples:

(5) man right: A term that is used by a man in an argument to prove that his point is indeed correct. It is over ruling over any women that may be present at the time. (UD 2018-05-18)

(6) manbola (man + ebola): An illness similar to manflu contracted only by men. This incapacitating illness can easily be confused with a cold or flu. When a man contracts Manbola only he knows and his loved ones should care for him accordingly. (UD 2018-05-18)

(7) man-flu: 1. Man-Flu is more painful than childbirth. This is an irrefutable scientific fact*. *(Survey of over 100,000 men) 2. Man-Flu is not 'just a cold'. It is a condition so severe that the germs from a single Man-Flu sneeze could wipe out entire tribes of people living in the rainforest. 3. Women do not contract Man-Flu. They suffer from what is medically recognised as a 'Mild Girly Sniffle' - which, if a man caught, he would still be able to run, tear the phone book in half and compete in all other kinds of manly activities. [...] (UD 2018-05-18) 
These first two examples aim at opposing men to women, and by reinforcing the differences, these man-neologisms also provide a definition of manhood. Example (7) introduces a related and recurrent notion present in the definitions of man-neologisms: superiority and/or excess. This characteristic seems to be an essential (i.e. prototypical) part in the definition of manhood. For example, 19 neologisms referring to FOOD AND DRINK (stereotypically associated with women) highlight the male aspect, which may seem contradictory. A closer look at the meaning of neologisms reveals that quantity and strength (for alcoholic drinks) are the main characteristics to define (superior) masculinity, sometimes in explicit opposition to women, as examples (8-11) illustrate.

(8) man bread: Bread that is baked so big that it will take a grown man a whole week to eat it, having 4 slices a day. (UD 2018-05-18)

(9) man-sip: A man sized sip of a beer or drink, one can finish a beer in 4 or 5 Man-sips. For a female or light weight, it borders on chugging the drink, but for a man it is merely a sip...hence the name Man-sip. (UD 2018-05-18)

(10) mantini (man + martini) (noun): a martini or alcoholic beverage that appeals to a man's palate. "My boyfriend prefers his mantini straight up which is just too strong for my tastes." (M.W. 2018-05-18)

(11) man cooler: Fruity bottled alcoholic drinks made to look like they are for men. i.e. Mikes Hard Lemonade, Parrot Bay, Smirnoff Ice, Reds Apple Ale, etc. "Dude, put down the Man Cooler, drink beer like a man." (UD 2018-05-18)

Most man-neologisms reinforcing differences appeal to a stereotypical image of manhood. However, another strategy used to reinforce differences is to depict women in stereotypical female actions. Women are not the main topic of man-neologisms, but they are nevertheless repeatedly referred to in the definitions. While FOOD AND DRINK are considered as part of the WOMAN frame, 32 man-neologisms pertain to this domain. However, references to women remain present, and in addition to the cases already mentioned above, man can be used to denote atypicality, as in man-slop which designates easily made food, illustrated in the following example:

(12) man-slop: Since no woman was around to make sandwiches, we decided to combine refried beans, corned beef hash, chili, two cans of sloppy joes sandwich sauce, and 10 slices of [American] cheese and pour it over bacon cheeseburgers, thus making man-slop. (UD 2018-05-18) (our emphasis)

All these examples show that man-neologisms aim at depicting men, but also serve an additional purpose, which is to contrastively depict women. Other examples are man chair, manscalator (man + escalator), man bench, and man seat which all refer to a place specifically for men. However, the male characteristic only makes sense in relation to women. Not only do these words share a reference to a place, they also simultaneously evoke typical female actions related to that place, as shown by the following examples:

(13) man chair: A man chair is the chair that men sit in while their partner is shopping for long periods of time. They can be found in almost any clothing or shoe store. What can we, as men do while our gf's or wives are shopping, we can sit in a man chair. (UD 2018-05-18)

(14) manscalator: wonderful form of a rotation of seats moving slowly along the mall... only for men to sit and enjoy watching [their] ...LADIES SHOP!! (UD 2018-05-18) 
Women are also often referred to concerning the domain HOME, which serves the same dual purpose: reinforcing its association with the WOMAN frame as well as strengthening differences. For instance, man-neologisms may refer to chores, an oft-cited illustration of inequalities between men and women, as shown by the following example:

(15) manchore: Chores men have to do, usually demanded of them by them Women folk. (UD 2018-05-18)

The examples above all illustrate how man-neologisms appeal to manhood in opposition to women, and often even highlight the inter-gender differences. However, manneologisms also introduce intra-gender differences, via two dimensions. The first dimension is age (young vs. old), typically in reference to physical strength, as in the following examples:

(16) man-strength: Used to describe the [surprising] ability of older men (e.g. your father in his 40-50s) to out-lift, out-drink, and generally out-work younger and more physically fit men. (UD 2018-05-18)

(17) man buff: The buff that only men have. Teenagers and grade schoolers can look buff or ripped, but they aren't man buff. Man buff is that look that only a man can gain. Man buff is accomplished with years of off and on going to the gym. To become man buff, one must have enough fat to look big enough to be man buff. One must lift high weight and low reps. Every [guy's] dream is [to] achieve man buff-ness. (UD 2018-05-18)

The second dimension is sexual orientation, which pertains to man-neologisms referring to RELATIONSHIPS: out of 132 references to relationships, 59 involve sexual orientation. Man can be used to refer to homosexual relationships, as in:

(18) mantrimony (noun): marriage of two men. (M.W. 2018-05-18)

Others, such as manbro, manpanion (man + companion), or manbrodude refer to male friendship excluding a sexual interpretation. Such explicit references to non-sexual relationships between men serve to distinguish heterosexual from homosexual men, which can be accompanied with a specific behaviour, as in:

(19) manBuddy: A straight guy uses this preferred reference to refer to his "boyfriends", because "boyfriend" just sounds too not-so-straight. (UD 2018-05-18)

(20) man buffer: The seat that two males must leave between each other when watching a movie together in an uncrowded theater. (UD 2018-05-18)

Specifying sexual orientations can reveal that relationships are not usually associated with the MAN frame, and the homophobic character of the definitions highlights this point. Numerous man-neologisms illustrate this atypicality by suggesting the suspicious nature of a relationship, as shown by example (21).

(21) Manationship (man + relationship): A non-gay but questionable relationship usually between close friends who are dudes. (UD 2018-05-18)

As with RELATIONSHIP, FEELING is regarded as a female domain. Man-neologisms concerning this domain do not refer to feelings but to their (apparent) absence, as shown by the following examples: 
(22) manblushing: When real men start to feel over happy but are too manly

to actually blush. (UD 2018-05-18)

(23) manblink: Men [...] try not to cry. (UD 2018-05-18)

To recapitulate, while man-neologisms significantly refer to female domains, this association is not to be interpreted as the elimination of differences; quite the contrary, they reinforce intra- and inter-gender distinctions in various ways, such as oppositions in terms of hierarchy, strength, or excess. While women are not the main referent of manneologisms, they are still typically evoked and depicted in typical 'female' actions, such as cooking or shopping.

\subsubsection{The confirmation of stereotypes}

The neologisms discussed so far all concerned female domains. Three male domains are, however, also involved in man-neologisms, viz, ABSTRACT NOTIONS, WORK and ENTERTAINMENT. As we will show below, the reinforcement of differences can be extended to neologisms designating male-oriented relations. These neologisms fit the study of stereotypes perfectly, as they 'double' the male aspect: they are man-specific and they refer to male domains.

Even if these neologisms differ from those reinforcing differences (which concern female domains), similar strategies are found. Like the neologisms mentioned in the previous section, they can highlight the male aspect or exclude women, as shown by the following examples.

(24) man science: - mæn saiəns - noun - a branch of knowledge often inherent in men and absent in women that allows for the programming of VCRs, lighting of pilot lights, and ability to problem solve. (UD 2018-05-18)

(25) mancation: When normal males engage in "guy" activities that involve sports, camping, gambling, chasing women and most of all drinking amongst their all and only male friends. No wives, mistresses or [girlfriends] allowed. Done in order [to] get in touch with their male-primal roots. (UD 2018-05-18) (26) man brain: the most [superior] of all brains. Compared to a "woman brain", the man brain has the ability to find directions, solve math problems, use common sense and logic as well as not being affected by drama/bitchery/ feminism. Those with a man brain find life much easier and more complete than those with other forms of brains. (UD 2018-05-18)

The last example reveals the similarity with the previous neologisms not only because of their reference to the exclusion of women, but also in their appeal to hierarchy or superiority. However, the exclusion is not necessarily total, and man can denote a male majority, as in mancession (man + recession; a recession (typically) affecting more men than women) or highlight the stereotype, shown by example (27), of men being more likely than women to choose a particular type of study or career.

(27) manconomics. Manconomics is [an] Economics classroom (Economics 101, macro, micro, etc) that is mostly dominated by men (maybe 1 - 2 women), therefore fitting the stereotype that women [don't] follow that career path. The classroom is [led] by an "alpha" male, most likely with a beard and a sense of humor (can also be called Godfather) (UD 2018-05-18) 
In short, neologisms pertaining to male-oriented relations and male domains confirm stereotypes using similar strategies as those used by neologisms that reinforce differences.

The neologisms discussed so far have men as their main reference point, even if their definitions often contain a reference to women, sometimes quite directly. More surprisingly perhaps is that women can also be the main target of man-neologisms, as in man book (a romantic novel for women), which is the case for 162 out 1,374 man-specific neologisms. A closer look at the meaning of these 'women-targeting' man-neologisms (which mainly refer to female domains as well), also reveal that similar strategies are used.

First, women-targeting neologisms pertaining to BODY AND HEALTH focus on distinguishing physical features that are atypical for women, as shown by example (28); note the phrasings unfeminine and overtly masculine in the definition.

(28) manceps: This is an unfeminine condition that occurs in women from lifting too many weights at the gym which leaves arms looking overtly masculine. The arms are extremely defined like a man's accompanied with bulging veins. (UD 2018-05-18)

Inter-gender distinctions are also introduced based on sexual orientation, as in examples (29) and (30).

(29) manbashingles: [one] who hates men, and bashes them, and is a lesbian in denial. (UD 2018-05-18)

(30) mansbian (man + lesbian): A lesbian in a man's body. (UD 2018-05-18)

Within neutral domains, such as BEHAVIOUR, hierarchy and exclusion are also involved to differentiate men and women, as shown in the following examples:

(31) mantality (man + mentality): (n) a masculine perspective adopted by women usually associated with dominance or entitlement. (UD 2018-05-18)

(32) manbitious (man + ambitious): When women try and do things that only a man can do - they are trying to be manbitious. (UD 2018-05-18)

Taken together, the three motivations presented above - the reappropriation of domains, the reinforcement of differences, and the confirmation of stereotypes - reveal that across and within domains man-neologisms are characterised by a considerable semantic heterogeneity and seeming contradictions: women acting like men versus men acting like women or men being attracted to women versus repulsed by women. Each domain and relation bring their own nuances and distinctions, to the extent that the only thing that appears to be common to all these man-neologisms is their form. Nevertheless, minimally, they do reveal a general and common need to define or reassert gender. Even though some neologisms aim at achieving an equality of domains, overall the specific nature of man-neologisms does not lead towards fewer differences. In addition, the strategies used to (re)assert these differences are fairly similar, across different domains. Despite the predominant gender-specific meaning, not all man-neologisms reinforce and/or introduce new distinctions. The man-specificity of neologisms can also be used to highlight and denunciate an undesirable male behaviour. 


\subsubsection{Naming undesirable male behaviours}

While man-neologisms can reinforce differences and confirm stereotypes, they can also highlight them, usually with the intention to change them. Remarkably, the following example summarises all the behaviours that have been presented so far.

(33) man box: The rules for "acting like a man"; the mentality, behaviors and restrictions that many men and boys are socialized to conform to. These tenets of the "cult of masculinity" are both symptoms and enablers of Dominator Culture. They can be so pervasive as to be almost invisible; yet they lead men to disrespect, mistreat, and abuse women and each other. THE MAN BOX: Demonstrate power/control (especially over women). Aggression - Dominance - yell - intimidate. Do not cry openly or express emotions (except for anger). Do not express weakness or fear - "take it". Don't back down - don't make mistakes. Do not be "like a woman". Heterosexual. Have lots of sex with women - "conquests". Do not be "like a gay man". Tough/ Athletic/Competitive/Strength/Courage. Make Decisions - Never ask for help. Women viewed as property/objects (especially sexual objects). (Based largely on Tony Porter's TED talk “A Call to Men") (UD 2018-05-18)

These behaviours are considered in relation to women, as are most man-neologisms that condemn attitudes, as shown by the following examples:

(34) manologue (noun): the long speech of a man who monopolizes a conversation: monologue by a man. "The manologue takes many forms, but is characterized by the proffering of words not asked for, of views not solicited and of arguments unsought. It is underwritten by the doubtful assumption that the audience will naturally be interested, and that this interest will not flag. -Julia Baird, The New York Times, April 20, 2016" (MW 2018-06-16)

(35) mansplain (verb): to explain (something) to a woman especially in a condescending way. (MW 2018-05-18)

(36) manshush: When a Man tries to "hush" a Woman for making an important point, usually when the Man knew that she is right, so one way to do is to STOP HER TALKING or SHUT HER UP or SILENCED HER. (UD 2018-05-18)

The last example is quite telling: while the meaning of hush implies a difference of authority which may in some contexts be justified (e.g. a teacher hushing too excited children); manshush clearly targets the unjustified authority relationship that men often assume towards women when they engage in conversation.

Yet, not all men are concerned by these neologisms, which can introduce distinctions between men as well, such as is the case for manarchy (man + anarchy) or manarchist (man + anarchist) which designate young, heterosexual, white, privileged men. Remarkably, these undesirable male behaviours towards women find interesting extensions to other kinds power relations in neologisms such as whitesplain (white + explain) or liberalsplain (liberal + explain).

Many of the dictionary definitions of neologisms designating an undesirable male behaviour refer to the feminist movement. Similar to the feminist movement of the 1960s and 1970s which encouraged women to become active in the language process by coining woman-centred words, the current feminist movement is accompanied by coinages of gendered words to make social practices visible. The naming of undesirable male 
behaviours echoes Spender's words in her chapter The Politics of Naming (1980) in which she highlights that naming women's experiences makes these experiences a less dubious reality. A nameless experience can make the experiencer believe that they are the first one to experience it, or that it is not a common experience. However, when one can name an experience or practice, all doubt on the reality of the experience is removed and it also becomes easier to condemn it. More recently, Manne [2017] voices similar observations, giving the example of himpathy, a neologism referring to the inappropriate and disproportionate sympathy powerful men often enjoy in cases of misogynistic behaviour (sexual assault, intimate partner violence, homicide, etc.). As she points out in an article in The New York Times (commenting on the appointment of Brett Kavanaugh as judge at the US Supreme Court despite allegations of sexual misconduct towards women), "Once you learn to spot himpathy, it becomes difficult not to see it everywhere" (Manne [2018]).

To recapitulate, the fourth motivation concerns neologisms which aim at highlighting undesirable male behaviours, such as mansplain or manspread, mostly with the intention to change such behaviours.

\subsection{Interim conclusion}

The semantic analysis of man-neologisms presented above aims at examining the current representation of gender in language. The results of our first investigation of manneologisms showed that the meaning of man is significantly gender-specific, suggesting that the generic meaning is not predominant in these coinages. The second investigation revealed that man-specific neologisms are mainly associated with domains of the WOMAN frame; we have identified four motivations for the (growing) tendency to coin these neologisms. The first motivation is the reappropriation of domains which corresponds to neologisms which designate female domains such as maiden name and man bag. While they show that a possible purpose is to erase differences, a more predominant motivation is the reinforcement of differences. This second motivation reveals that, even though neologisms refer to female domains, the male specific nature of these neologisms is more inclined to reinforce intra- and inter-gender distinctions. Thus, men are depicted with reference to female domains, but are, or remain, associated with typical male characteristics, such as strength or excess and they are thus (more sharply) distinguished from women. The association of men with male characteristics is confirmed by manneologisms which denote male domains. These neologisms revealed the third motivation, the confirmation of stereotypes. Not only do neologisms reinforce differences when associated with female domains, they are also associated with domains which are already male. Moreover, women-oriented man-neologisms (which have women as the main reference point) which could have enabled a symmetry between the reappropriation of male and female domains and genders turn out not to appeal to male domains. While these three motivations share the need to define gender, the fourth motivation is directly related to the current context of increased gender-awareness. Indeed, neologisms that name undesirable male behaviours increase the visibility of these behaviours and possibly facilitate their denunciation. Overall, the semantic analysis reveals that man-neologisms are undoubtedly at variance, but not in direct conflict, with approaches advocating the gender neutralisation of language.

One limitation of the semantic analysis presented here is that using the Urban Dictionary as the main source of man-neologisms may have triggered an over-representation of 
certain types of neologisms. Our qualitative analysis of the meaning of man-neologisms does not enable us to make general claims about the representation of gender in language overall, as it does not take usage and productivity into account. The various semantic characteristics revealed by our analysis can, however, form the basis for such a study of the diffusion of man-neologisms looking at which semantic features are reliable predictors of the conventionalisation of neologisms and which gender representation is predominant in language.

The following section presents the onset of such a more quantitative analysis, in the form of a small study of the diffusion of man-specific neologisms using the corpus iWeb. ${ }^{9}$ More specifically, we aim at observing which motivations favour the diffusion of neologisms.

\section{Diffusion of man-neologisms}

\subsection{Data and method}

The analysis of the diffusion of man-neologisms was carried out based on a frequency analysis using the iWeb corpus. The scope of the current study remains fairly modest, as we have only looked at frequency of occurrence to assess the degree of diffusion of manneologisms, and not at other contextual features. The method that we have used is as follows. We checked the frequency in the iWeb corpus of each neologism from our dictionary sample. Each attestation was manually checked to ensure that it was not a mismatch. For example, the search for the neologism man blush, yielded 17 occurrences which, however, were all instances of the VP man blush (as in To make man blush there was but one) and not of the neologism in question, which did not appear in the corpus. False hits such as these were obviously disregarded. The frequency of occurrences varied from 0 to 7,408 .

The man-neologisms were subsequently labelled according to the four motivations presented above: (i) REAPPROPRIATION (the reappropriation of domains), (ii) DIFFERENCES (the reinforcement of differences), (iii) STEREOTYPES (the confirmation of stereotypes), (iv) NAMING (naming undesirable male behaviours), and finally (v) NEUTRAL. The last category subsumes neologisms which do not correspond to any of the other categories, which are neologisms denoting chimeras such as manango (man + mango). The distribution of man-neologisms into these five categories is presented in Table 3.

Table 3: The distribution of man-neologisms into semantic categories

\begin{tabular}{|l|l|l|}
\hline CATEGORIES & N & \% \\
\hline REAPPROPRIATION & 185 & $13 \%$ \\
\hline DIFFERENCES & 933 & $68 \%$ \\
\hline STEREOTYPES & 211 & $15 \%$ \\
\hline NAMING & 34 & $2 \%$ \\
\hline NEUTRAL & 11 & $1 \%$ \\
\hline
\end{tabular}




\begin{tabular}{|l|l|l|}
\hline TOTAL & 1,374 & $100 \%$ \\
\hline
\end{tabular}

The occurrences were further grouped into frequency groups representing their degrees of diffusion; these are presented in Table 4, which also gives the exact number of neologisms in each group.

Table 4: Man-neologisms and categories of diffusion

\begin{tabular}{|l|l|}
\hline CATEGORY & N \\
\hline 0 (0 occurrence $)$ & 1,030 \\
\hline 1 (1-10 occurrences $)$ & 233 \\
\hline 2 (11-100 occurrences) & 86 \\
\hline 3 (>100 occurrences $)$ & 25 \\
\hline TOTAL & 1,374 \\
\hline
\end{tabular}

\subsection{The diffusion of man-neologisms}

The aim of a frequency-based diffusion analysis of man-neologisms is to uncover which motivations enable (or encourage) the diffusion of neologisms. To do so, we crossed the degree of diffusion and the motivation, presented in Table 5 and Figure 1.

As the number of neologisms in each category of motivations varies considerably (cf. Table 3), the distribution of neologisms in the categories of diffusion has been normalised to relative frequencies (percentages) to be able to compare the proportion of neologisms in each category of diffusion between the various motivations.

Table 5: Distribution of the motivations of man-neologisms into degrees of diffusion

\begin{tabular}{|l|l|l|l|l|l|}
\hline $\begin{array}{l}\text { DIFFUSION } \\
\text { MOTIVATION }\end{array}$ & $\mathbf{0}$ & $\mathbf{1}$ & $\mathbf{2}$ & $\mathbf{3}$ & TOTAL \\
\hline Reappropriation & $67.03 \%$ & $20.54 \%$ & $10.27 \%$ & $2.16 \%$ & $100 \%$ \\
\hline Differences & $77.60 \%$ & $15.76 \%$ & $5.47 \%$ & $1.18 \%$ & $100 \%$ \\
\hline Stereotypes & $74.41 \%$ & $18.96 \%$ & $4.74 \%$ & $1.90 \%$ & $100 \%$ \\
\hline Naming & $44.12 \%$ & $23.53 \%$ & $17.65 \%$ & $14.71 \%$ & $100 \%$ \\
\hline Neutral & $90.91 \%$ & $0.00 \%$ & $0.00 \%$ & $9.09 \%$ & $100 \%$ \\
\hline TOTAL & $\mathbf{7 4 . 9 6 \%}$ & $\mathbf{1 6 . 9 6 \%}$ & $\mathbf{6 . 2 6 \%}$ & $\mathbf{1 . 8 2} \%$ & $\mathbf{1 0 0 \%}$ \\
\hline
\end{tabular}




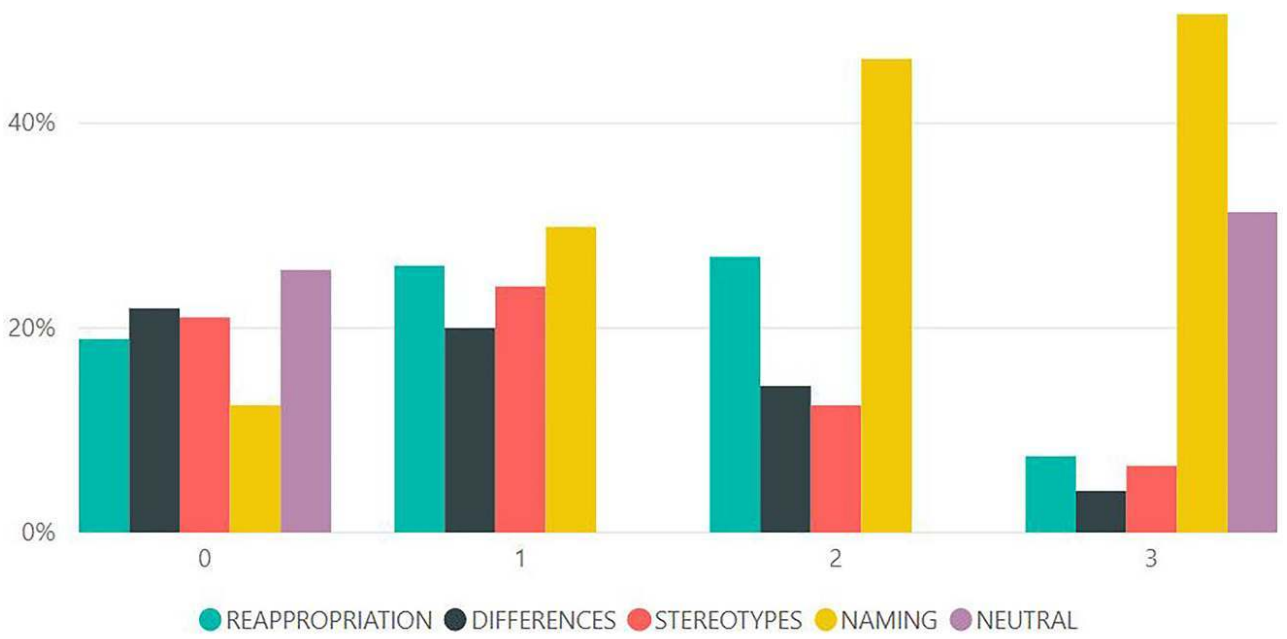

Overall, the results represented in Table 5 show that there is a higher proportion of neologisms with no occurrences (category 0) than neologisms with more frequent occurrences (category 3). More specifically, for the four motivations, the proportion of neologisms from category 0 to 3 decreases.

This is not the case of the fifth category NEUTRAL, in which no neologisms appear in category 1 and 2, but they do in category 3 . This is due to the neologism manbearpig which refers to a fictitious animal (a combination of a man, a bear, and a pig) in the tv-show South Park. Disregarding the category NEUTRAL (which is not very relevant here), the predominant trend illustrated by most categories (i.e. REAPPROPRIATION, DIFFERENCES, and STEREOTYPES) is a decreasing proportion of neologisms with fewer occurrences, if any at all, for the higher degrees of diffusion.

The motivation of naming undesirable male behaviours differs from the other motivations. Firstly, this category has the lowest proportion of no occurrences (category 0 ). Furthermore, while it follows the main downward trend of having fewer neologisms as the degree increases, this decrease is less outspoken and it forms the highest proportion of man-neologisms in category 3, which is due to two particular neologisms, mansplain and manspread.

The category REAPPROPRIATION follows a similar trend even though less clearly so; the results are especially due to neologisms such as man bun, mankini and man bag.

Despite the modest scope of our study, these results allow us to distinguish creative from productive motivations. While there is a proliferation of gendered coinages, most of them are ad-hoc formations rather than neologisms per se. This is particularly true of manneologisms reinforcing differences and confirming stereotypes. The number of coinages that correspond to these motivations is higher, but they are less diffused, as they occur less frequently. Thus, the reinforcement of differences and confirmation of stereotypes can be defined as creative motivations. On the other hand, man-neologisms aiming at the reappropriation of the female domain and more particularly, those naming undesirable behaviours are not coined as often as the other ones (fewer types), but they tend to be more diffused and to occur more frequently. Thus, these two motivations, and in 
particular the NAMING strategy, can be regarded as (more) productive. This should not come as a surprise: man-neologisms corresponding to these two motivations appear in a gender-awareness context where social practices and new trends related to gender are repeatedly discussed, revised and, importantly, named. The current (\#MeToo) context of gender-discussion may explain the higher degree of diffusion of man-neologisms naming undesirable male behaviours, as their main purpose is precisely to name these behaviours and, by doing so, making them visible.

\section{Conclusion and prospects}

Through the study of a specific type of gendered coinages, man-neologisms, this article has looked at the various representations of gender in language. The semantic analysis of these neologisms revealed, firstly, that the great majority of them concern a genderspecific rather than a generic meaning. We have suggested four motivations underlying the creation of man-specific neologisms: (i) the reappropriation of domains which are typically associated with women, as in man purse (a purse for men); (ii) the reinforcement of differences, such as man cave (a room for men only); (iii) the confirmation of stereotypes, as in man science (a branch of knowledge available to men only); and (iv) naming undesirable male behaviours, mainly in an attempt to change them, such as mansplain. While our semantic analysis has revealed the various representations of gender in language, no reliable generalisations can yet be made on the basis of our study, as these man-neologisms have not been evaluated on their degree of diffusion. Nevertheless, looking at the type and token frequency of man-neologisms revealed that neologisms that name undesirable male behaviours have a lower number of types in our dictionary sample of coinages (and are thus perhaps less likely to be coined compared to those based on the other motivations), but as indicated by the data from the iWeb corpus, they are used more frequently (higher token frequency). Conversely, neologisms aiming at reinforcing differences and confirming stereotypes were more numerous in our dictionary sample, but are less diffused, which suggests that they remain ad-hoc formations. The corpus study reveals that the visibility of male behaviours is the predominant factor at issue in man-neologisms; these results line up with the current gender-awareness context in which social practices, and particularly undesired ones, are repeatedly discussed and revised.

A natural progression of this work is to expand our study to the motivations for, and degrees of diffusion of, gender-neologisms by including other coinages such as bromance, guyliner (guy + eyeliner), girlboss or mumtrepeneur (mum + entrepreneur). As the sheer quantity of man-neologisms shows, there is a strong trend to coin such gendered neologisms. This would also include looking at (frequent) coinages of woman-specific neologisms, such as woman cave and woman cold. A contrastive analysis of the woman- and man-neologisms in terms of meanings and usage could provide valuable information. Furthermore, the diffusion analysis should be extended by observing additional contextual factors, since the degree of diffusion of a neologism should also include other contextual factors, such as genre and/or register, the gender and social position of the speaker, etc. Only then can a true appreciation of gendered-neologisms be attained. 


\section{BIBLIOGRAPHY}

BAUER Laurie, 1983, English Word-Formation, Cambridge: Cambridge University Press.

CHATARD Armand, GUIMOND serge \& MARTINOT Delphine, 2005, « Impact de la féminisation lexicale des professions sur l'auto-efficacité des élèves : une remise en cause de l'universalisme masculin? », L’Année Psychologique, 105 (2), 249-272.

FISCHER Roswitha, 1998, Lexical Change in Present-Day English: A corpus-based study of the motivation, institutionalization, and productivity of creative neologisms, Tübingen: Gunter Narr Verlag.

FOUBERT Océane, 2018, Gender Representation in English, Unpublished MA dissertation, Université de Lille, France.

GAUCHER Danielle, FRIESEN Justin \& KAY Aaron, 2011, "Evidence that gendered wording in job advertisement exists and sustains gender inequality", Journal of Personality and Social Psychology, $101(1), 109-128$

GRIES Stefan Th., 2004, "Some characteristics of English morphological blends" in ANDRONIS Mary A., DEBENPORT Erin, PYCHA Anna \& YOSHIMURA Keiko (eds.), Papers from the $38^{\text {th }}$ Regional Meeting of the Chicago Linguistics Society: Vol. 2, The Panels, Chicago, IL: Chicago Linguistics Society, 201-216.

GRIES Stefan Th., 2012, "Quantitative corpus data on blend formation: Psycho- and cognitivelinguistic perspectives”, RENNER Vincent, MANIEZ François \& ARNAUD Pierre (eds.), Cross-Disciplinary Perspectives on Lexical Blending, Berlin/New York: Mouton de Gruyter, 145-167.

HAAS Mary, 1944, “Men's and women's speech in Koasati”, Language, 20 (3), 142-149.

HELLINGER Marlis \& BUBMANN Hadumod, (eds.), 2001, Gender across languages: The linguistic representation of women and men, Vol. 1, Amsterdam/Philadelphia: John Benjamins Publishing Company.

HELLINGER Marlis \& BUBMANN Hadumod, (eds.), 2002, Gender across languages: The linguistic representation of women and men, Vol. 2, Amsterdam/Philadelphia: John Benjamins Publishing Company.

HELLINGER Marlis \& BUBMANN Hadumod, (eds.), 2003, Gender across languages: The linguistic representation of women and men, Vol. 3, Amsterdam/Philadelphia: John Benjamins Publishing Company.

HELLINGER Marlis \& BUBMANN Hadumod, (eds.), 2015, Gender across languages: The linguistic representation of women and men, Vol. 4, Amsterdam/Philadelphia: John Benjamins Publishing Company.

Kemmer Suzanne, 2003, "Schemas and lexical blends", in CuycKens Hubert, Berg thomas, DiRven René \& PANTHER Klaus-Uwe (eds.), Motivation in Language: Studies in Honor of Günter Radden, Amsterdam/Philadelphia: John Benjamins Publishing Company, 69-97.

LAKOFF Robin, 1975, Language and Women's Place, New York/Hagerstown/San Francisco/London: Harper \& Row.

LEHRER Adrienne, 1996, "Identifying and interpreting blends: An experimental approach", Cognitive Linguistics, 7 (4), 359-390. 
MANNE Kate, 2017, Down Girl. The Logic of Misogyny, Oxford: Oxford University Press.

MANNE Kate, 2018, “Brett Kavanaugh and America's 'Himpathy' Reckoning”, The New York Times, Sept. 26, 2018. [available at: https://www.nytimes.com/2018/09/26/opinion/brett-kavanaughhearing-himpathy.html; last accessed: Nov. 27, 2018].

TANNEN Deborah, 1990, You Just don't Understand: Women and men in conversation, New York: William Morrow \& Co.

SCHMID Hans-Jörg, 2003, "Do women and men really live in different cultures? Evidence from the BNC", in WILSON Andrew, RAYSON Paul \& MCENERY Tony (eds.), Corpus Linguistics by the Lune: A Festschrift for Geoffrey Leech, Frankfurt: Peter Lang, 185-221.

SCHMID Hans-Jörg, 2016, English Morphology and Word-Formation: An introduction, Berlin: Schmidt Verlag.

SCZESNY Sabine, FORMANOWICZ Magda \& MOSER Franziska, 2016, “Can gender-fair language reduce gender stereotyping and discrimination?", Frontiers in Psychology, 7, 1-11.

SPENDER Dale, 1980, Man made language, London/Boston/Sydney/Wellington: Pandora Press.

STAHLBERG Dagmar, BRAUN Friederike, IRMEN Lisa \& SCZESNY Sabine, 2007, "Representation of the sexes in language", in FIEDLER Klaus (ed.), Social communication. A volume in the series Frontiers of Social Psychology, New York: Psychology Press, 163-187.

UNESCO, 1999, Guidelines for gender-neutral language. available at http://unesdoc.unesco.org/ images/0011/001149/114950mo.pdf [Accessed 19 June 2018]

VERVECKEN Dries, HANNOVER Bettina \& WOLTER Ilka, 2013, “Changing (S)expectations: How genderfair job descriptions impact children's perceptions and interest regarding traditionally male occupations", Journal of Vocational Behavior, 82 (3), 208-220.

WURSCHINGER Quirin, ELAHI Mohammed Fazleh, ZHEKOVA Desislava \& SCHMID Hans-Jörg, 2016, "Using the web and social media as corpora for monitoring the spread of neologisms. The case of rapefugee, rapeugee, and rapugee", Proceedings of the $10^{\text {th }}$ Web as Corpus Workshop (WAC-X) and the EmpiriST Shared Task, Berlin, Germany, 35-43.

\section{Corpora}

DAVIES Mark, 2018, The 14 Billion Word iWeb Corpus. Available online at https://corpus.byu.edu/ iWeb/

The Open Dictionary, http://nws.merriam-webster.com/opendictionary/

The Urban Dictionary, https://www.urbandictionary.com/

\section{NOTES}

1. We thank the two anonymous reviewers for their valuable comments on a previous version of this article.

2. For blends, we will systematically provide the source words between brackets.

3. The Open Dictionary (http://nws.merriam-webster.com/opendictionary/) is a collection of words submitted by Merriam-Webster's users. Accepted for this collection are attested words which do not (yet) have an entry in a dictionary. Personal coinages are not accepted. The Urban Dictionary (https://www.urbandictionary.com/), in turn, is an online dictionary that was founded in 1999. Volunteer editors can decide on the publication of definitions. It has repeatedly been 
criticised for the sometimes purposely-offensive character of some definitions to discredit people. This dictionary has allowed us, however, to collect a wider range of gendered neologisms. While this dictionary has been our main resource for the collection of man-neologisms, only a diffusion analysis can determine whether they are representative of the representation of gender in language.

4. One could argue that qualifying a domain as either male or female (or neutral) requires independent (i.e. non-linguistic) criteria; while this seems a straightforward enough endeavour, it raises other methodological difficulties which may be even harder to overcome. Using stereotypical associations based on predominant discourse topics thus seems a valid starting point for a linguistic analysis of gendered neologisms.

5. This code refers to the sources of the data (UD for Urban Dictionary and MW for Merriam-Webster ); it is followed by the date of its last access. All the definitions mentioned in this article have been taken over from these sources as they were.

6. As one of the reviewers points out, another difference is that the uses of man as in chairman or policeman are always pronounced with a reduced vowel, which is not the case of man used in the man-neologisms studied here. While this is clearly so, this may (but need not) disappear in the plural form (policemen). In addition, it cannot be excluded that the (recurrent) homography with the lexeme man may still play a role, much more so than for an occasional reduction coinciding with semantic loss, as in cupboard. Despite the phonological difference, we suggest that also the reduced form still activates the semantics of the lexeme man; alternative forms such as police woman or chairwoman could be taken as illustration of this (even if one cannot exclude that they were created for a social purpose rather than a cognitive-semantic one).

7. Statistical analyses were done in R (www.r-project.org).

8. We thank one of the reviewers for bringing this to our attention.

9. The iWeb corpus is a corpus based on about 14 billion words in 22 million web pages from about 95,000 websites; it is available at https://corpus.byu.edu/iweb/

\section{ABSTRACTS}

This article presents a semantic and frequency-based diffusion analysis of one specific type of gendered coinages that we will refer to as "man-neologisms" such as man bun, mancation (man + vacation) or manspread. Our study (based on Foubert [2018]) reveals that man in these coinages only rarely carries a generic meaning (referring to human beings in general, as in man is mortal) but mostly have a gender-specific meaning ("of, or related to, men"). Our analysis of the meanings of these man-specific neologisms shows that they are gender specific and mainly concern domains which are typically associated with women. Moreover, our analysis reveals four motivations behind the coinages of man-neologisms: (i) the reappropriation of domains which are typically associated with women, as in man purse (a purse for men), (ii) the reinforcement of differences, such as man cave (a room for men only), (iii) the confirmation of stereotypes, as in man science (a branch of knowledge available to men only), (iv) and naming undesirable male behaviours, mainly in an attempt to change them, such as mansplain (man + explain; men explaining things to women in a condescending way). The diffusion analysis observing the frequency of occurrences of man-neologisms reveals that neologisms aiming at the reappropriation of domains and particularly those naming undesirable male behaviours are less 
numerous in the list of coinages themselves, but more inclined to be diffused, contrary to neologisms reinforcing differences and confirming stereotypes.

Cet article présente l'analyse sémantique et la diffusion de néologismes genrés en anglais que l'on appellera "man-neologisms" tels que man bun, mancation (man + vacation) et manspread. Notre étude (basée sur Foubert [2018]) montre que l'usage de man dans ces néologismes ne se réfère que très peu à son sens générique (les êtres humains en général, comme dans Homme) mais se réfère plutôt au sens spécifique (homme). Notre analyse sémantique des néologismes avec ce sens spécifique montre qu'ils sont spécifiques par le fait qu'ils désignent majoritairement des domaines typiquement associés aux femmes. De plus, notre étude révèle quatre motivations à l'origine de ces néologismes : (i) se réapproprier des domaines typiquement associés aux femmes, tel que man purse (un sac à main pour les hommes), (ii) cultiver les différences, tel que man cave (une pièce réservée aux hommes), (iii) conforter les stéréotypes, tel que man science (des connaissances qui ne sont disponibles qu'aux hommes), et (iv) nommer des comportements masculins indésirables, en ayant pour but de les changer, tel que mansplain (man + explain, ou mecspliquer: quand un homme explique quelque chose de façon condescendante). L'analyse portant sur la diffusion étudie la fréquence des occurrences des néologismes; les résultats montrent que les néologismes qui visent à se réapproprier des domaines et plus particulièrement ceux qui visent à nommer des comportements masculins sont numériquement peu représentés dans les formations nouvelles, mais utilisés fréquemment, à l'inverse des néologismes qui cultivent les différences et confortent les stéréotypes.

\section{INDEX}

Keywords: neologism, gender, lexical semantics, diffusion

Mots-clés: néologie, genre, sémantique lexicale, diffusion

\section{AUTHORS}

\section{OCÉANE FOUBERT}

UMR 8163 STL (Savoirs, Textes, Langage), CNRS et Université de Lille, France oceane.foubert.etu@univ-lille.fr

\section{MAARTEN LEMMENS}

UMR 8163 STL (Savoirs, Textes, Langage), CNRS et Université de Lille, France maarten.lemmens@univ-lille.fr 